\title{
Necrotizing fasciitis of the breast
}

\author{
Saira Nizami \\ Aga Khan University \\ Kamran Mohiuddin \\ Aga Khan University \\ Mohisin-e-Azam \\ Aga Khan University \\ Hasnain Zafar \\ Aga Khan University, hasnain.zafar@aku.edu \\ Muhammad Ashraf Memon \\ Whiston Hospital, United Kingdom
}

Follow this and additional works at: https://ecommons.aku.edu/pakistan_fhs_mc_surg_gen

Part of the Surgery Commons

\section{Recommended Citation}

Nizami, S., Mohiuddin, K., Mohisin-e-Azam, ., Zafar, H., Memon, M. (2006). Necrotizing fasciitis of the breast. The Breast Journal, 12(2), 168-169.

Available at: https://ecommons.aku.edu/pakistan_fhs_mc_surg_gen/52 


\title{
CASE REPORT
}

\section{Necrotizing Fasciitis of the Breast}

\author{
Saira Nizami, FCPS, MRCS, ${ }^{* \dagger}$ Kamran Mohiuddin, FCPS, MRCS, *† \\ Mohsin-e-Azam, MBBS, * Hasnain Zafar, FRCS, ${ }^{*}$ and \\ Muhammed Ashraf Memon, FRCS ${ }^{\dagger}$ \\ *Department of Surgery, Aga Khan University Hospital, Karachi, Pakistan; and ${ }^{\dagger}$ Department of Surgery, \\ Whiston Hospital, Warrington Road, Prescot, Merseyside, United Kingdom
}

Abstract: Necrotizing fasciitis is a potentially fatal condition that can affect any part of the body. It can occur after trauma, around foreign bodies in surgical wounds, or can be idiopathic. We describe a case of necrotizing fasciitis involving the breast following an initial debridement of an inflammatory lesion.

Key Words: breast, necrotizing fasciitis, polymicrobial infection

\section{CASE REPORT}

A 54-year-old postmenopausal Asian woman presented with a 6-day history of a painful lesion on her right breast which was associated with purulent discharge and high-grade fever for the last 3 days. She had hypertension, asthma, and steroid-dependent arthritis. Her mother died of breast cancer at the age of 50 years. She was already on oral Augmentin for the last 2 days which was prescribed by her general practitioner.

On admission, she had a temperature of $38.5^{\circ} \mathrm{C}$ and a pulse of $110 / \mathrm{min}$. Local examination of the right breast revealed a $6 \mathrm{~cm} \times 6 \mathrm{~cm}$ ulcer involving the outer quadrant. The margins of the ulcer were indurated with cellulitis and peau d'orange involving the whole breast. There was no nipple discharge or palpable axillary lymph nodes. Examination of the left breast and axilla was within normal limits.

Routine blood investigations at the time of admission revealed a white cell count of $34.6 \times 10^{9} / \mathrm{L}$ with $94 \%$ neutrophils. Ultrasound of the breast reported altered parenchymal echotexture in the outer half and around the areolar region with irregular diffuse thickening of the skin. There were no definite focal discrete solid or cystic lesions and therefore no fine-needle aspiration was performed. With an initial assessment of a soft tissue infection, oral Augmentin was converted to an intravenous method and

Address correspondence and reprint requests to: M. A. Memon, FRCS, Astley House, Whitehall Road, Darwen, Lancashire BB3 2LH, UK, or e-mail: mmemon@yahoo.com.

(C) 2006 Blackwell Publishing, Inc., 1075-122X/06

The Breast Journal, Volume 12 Number 2, $2006168-169$ surgical debridement was planned. Intraoperatively, the infective focus involved only the skin, with completely normal underlying breast tissue. Multiple biopsies revealed acute pyogenic inflammation with no evidence of malignancy. The patient was discharged on the second postoperative day on oral Augmentin and was advised to return to the clinic 24 hours later.

Reexamination of the lesion at that stage revealed that the surrounding inflammation had become more extensive and florid with surrounding discoloration (Fig. 1). The patient was therefore readmitted for broad-spectrum intravenous antibiotics (aerobic and anaerobic cover) and a repeat debridement. The second debridement, performed within 48 hours of the initial surgery, showed

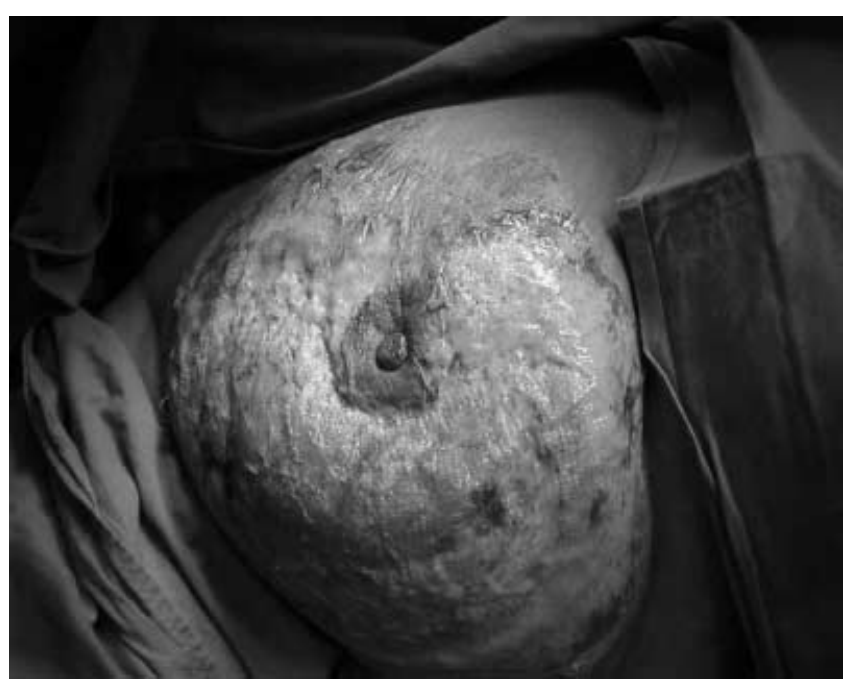

Figure 1. Necrotizing fasciitis of the breast. 
extensive necrosis of the entire breast (skin and breast tissue). A simple mastectomy was performed along with an extensive excision of the involved skin.

The histopathology of the specimen confirmed extensive acute pyogenic inflammatory infiltrate with abscess formation and extensive areas of necrosis. Gram stain revealed polymicrobial infection. No evidence of malignancy was seen.

The patient's initial postoperative course was stormy, but she eventually made a complete recovery. Subsequent postoperative assessment showed no further extension of the necrosis, with healthy granulation tissue formation. After 2 weeks the extensive overlying skin defect was closed by the plastic surgeons using a split-thickness skin graft without any complications.

\section{DISCUSSION}

Necrotizing fasciitis was first defined by Wilson in 1952 as necrosis of the fascia and subcutaneous tissue with sparing of the muscle (1). Patients susceptible to this infection include those with advanced age, chronic renal failure, peripheral vascular disease, and diabetes mellitus. Although it can affect any part of the body, the sites most frequently involved include the extremities, the scrotum (Fournier's gangrene), and the perineal region (2). If diagnosed at a late stage, it may result in septic shock, multiorgan failure, and death. Diagnosis is based on clinical examination showing signs of inflammation with a skin color change from red-purple to dusky blue (2,3). Most importantly, severe pain disproportionate to local findings along with systemic toxicity should raise the suspicion of necrotizing fasciitis. Management includes supportive treatment with broad-spectrum antibiotics to cover the polymicrobial nature of necrotizing fasciitis and early aggressive surgical debridement. Depending on the patient's clinical status, intensive care treatment may be needed with multiple visits to the operating room. Unfortunately this condition still carries high morbidity and mortality rates $(2,3)$.
Shah et al. (4) reported the first case of necrotizing fasciitis of the breast in the English-language literature. This patient was diabetic and the presentation was very similar to ours. A simple mastectomy with delayed closure of the wound led to full recovery. The diagnosis of necrotizing fasciitis was confirmed histologically. Euguster et al. (5) also reported two cases of necrotizing fasciitis in the Swiss literature after surgical intervention on the breast. Unfortunately both of their patients died of beta hemolytic streptococci sepsis. Similarly our patient was immunocompromised, as she was on steroids. Furthermore, her initial insult was surgical debridement, which in the presence of her immunocompromised status led to florid polymicrobial necrotizing infection of her breast. We feel that her successful surgical outcome was secondary to expeditious surgical intervention in the form of wide local excision of the breast tissue along with broad-spectrum antibiotics.

\section{CONCLUSION}

Necrotizing fasciitis is a rare condition and a high index of suspicion is required to diagnose it. An aggressive resuscitation, followed by speedy surgical debridement in conjunction with broad-spectrum antibiotic therapy is the mainstay of treating this condition successfully, which otherwise carries high morbidity and mortality rates.

\section{REFERENCES}

1. Wilson B. Necrotizing fasciitis. Am Surg 1952;18:416-31.

2. Hasham S, Matteucci P, Stanley PR, Hart NB. Necrotising fasciitis. BMJ 2005;330:830-33.

3. Singh G, Sinha SK, Adhikary S, Babu KS, Ray P, Khanna SK. Necrotising infections of soft tissues-a clinical profile. Eur J Surg 2002;168:366-71.

4. Shah J, Sharma AK, O'Donoghue JM, Mearns B, Johri A, Thomas V. Necrotising fasciitis of the breast. Br J Plast Surg 2001;54:67-68.

5. Eugster T, Aeberhard P, Reist K, Sakmann K. Necrotizing fasciitis caused by beta-hemolytic streptococci with fatal outcome-a case report. Swiss Surg 1997;3:117-20. 